\title{
La religiosidad popular como "entre-medio" entre la religión institucional y la espiritualidad individualizada
}

\section{Popular religion as "in between" institutional religion and individual spirituality}

Renée de la Torre*

\begin{abstract}
Resumo: Neste artigo se argumenta a relevância do estudo da religiosidade popular para entender as novas formas da religiosidade contemporânea no contexto latinoamericano. Diferente das posturas teóricas dos sociólogos da religião europeia, que assinalam a pertinência do indivíduo como unidade analítica para entender as transformações religiosas próprias da pós-modernidade, este artigo argumenta que a religiosidade popular - entendida como "entre-meio" entre o tradicional e o emergente, entre o local e o transnacional, entre o social e o individual e entre a sacralidade profana e a profanação da religiosidade tradicional - permite entender os fenômenos em que a religiosidade se pratica nas margens da instituição (próprias das expressões new age e neoesotéricas), mas sem desatender os processos em que se legitimam as novas formas desinstitucionalizadas da religiosidade, buscando âncoras e linhagens que geram a continuidade do peso da tradição da religiosidade popular.
\end{abstract}

Palavras-chave: América Latina; religião popular; new age; neoesotérica

\begin{abstract}
In this paper it is proposed that the study of popular religiosity is relevant to understanding new forms of contemporary religiosity as they emerge in Latin America. Whereas the theoretical positions held by sociologists of religion in Europe assume that the individual is the most suitable unit for analysis in order to understand the religious transformations of postmodern times, it is argued in this paper that popular religion, understood as being "in between" the traditional and the newly arising, between the local and the transnational, between the social and the individual and between the holiness of the worldly and the worldliness of the sacred, makes it possible to take into account the phenomena of religion practised on the margins of the institutions (as in its new age and neo-esoteric expressions); while attending to the processes by which the

* Profesora-Investigadora del Centro de Investigaciones y Estudios Superiores en Antropología Social (Ciesas) de Occidente. Es miembro del SNI Nivel II, y de la Academia Nacional de la Ciencia. El actual artículo retoma varios elementos de las conclusiones de su libro más reciente (De la Torre 2012).<renee@ciesas.edu.mx>
\end{abstract}

\begin{tabular}{|l|l|l|l|l|l|}
\hline Civitas & Porto Alegre & v. 12 & n. 3 & p. 506-521 & set.-dez. 2012 \\
\hline
\end{tabular}


new de-institutionalised forms of religion legitimate themselves, seeking anchorages and lineages that would create a continuity with the weight of tradition provided by popular religion.

Keywords: Latin America; popular religion; new age; neo-esoteric

Lo religioso es una dimensión transversal del fenómeno humano, que opera, de manera activa o latente, explícita o implicita, en todo el espesor de la realidad social, cultural y psicológica, según modalidades propias a cada una de la civilizaciones en el seno de las cuales uno se esfuerza por identificar su presencia.

HERVIEU-LĖGeR, 2004, p. 17-18

¿Por qué proponer estudiar la religiosidad popular en la actualidad? Es la pregunta que guía este artículo. Mientras que los sociólogos de los países europeos y norteamericanos se debaten entre dos posturas paradigmáticas: por un lado, bajo la premisa de que vivimos en una modernidad cuya racionalidad instrumental, se plantean el estudio de la competencia entre esferas sociales, instituciones, o campos especializados. En este terreno se desarrollan los estudios comparativos sobre modelos de laicidad, es decir de las relaciones entre el Estado y las iglesias, concentrándose en la descripción y el análisis de los marcos institucionales con fronteras específicas y formas de organización altamente burocratizadas, especializadas y autónomas. Este modelo circunscribió el estudio del fenómeno religioso al estudio de las religiones, de sus formas especializadas de gestión y de la competencia de ellas con otras instituciones y entre sus campos o ámbitos especializados. Diversos estudios latinoamericanos estuvieron influidos por los modelos teóricos de la sociología de Pierre Bourdieu y su concepto de campo religioso.

Por otro lado, la concepción posmoderna o de la modernidad tardía, supone la fragmentación del sentido de la modernidad, lo cual lleva a plantear dos tendencias que desregularizan el campo religioso: la desinsitucionalización y la individualización. Heelas y Woodhead (2005) llegaron a plantear que la nueva espiritualidad está centrada en la experiencia interior, generando una progresiva disolución de las formas tradicionales de compromiso con o sagrado. Se sugiere con ello que la religión ha salido de las instituciones, y ha sufrido un estallido, mediante el cual las grandes doctrinas y religiones tradicionales se han desmoronado, y se recomponen en religiosidades a la carta, es decir en consumos aleatorios, selectivos e individualizados, en los 
que cada individuo va conformando su propio menú personalizado, tomando prestados elementos provenientes de diferentes marcos tradicionales (HervieuLèger, 1996).

Aunque pareciera a simple vista que habría que tomar una postura por una u otra propuesta teórica, considero que será mejor buscar: a) una respuesta conceptual alternativa, que, en el plano teórico, nos permita superar el dilema entre lo institucional y lo individual; b) que en el plano histórico nos permita reconocer las particularidades históricas de la religión en América Latina; y c) que no desconozca los aportes de los cientistas sociales latinoamericanos sobre el entrecruce entre lo tradicional y las formas en la religiosidad popular en América Latina, las cuales expondré a partir de los hallazgos propios de mi trabajo de investigación en México. Estos tres aspectos, serán los que darán forma a la argumentación a desarrollar en este trabajo.

\section{Una respuesta conceptual alternativa al dilema entre lo institucional y lo individual}

Por un lado, quienes privilegian el estudio de los avances de la secularización en la sociedad actual, la mayoría de las veces descuidan atender los procesos adaptativos y de reconquista que ejercen las religiones sobre aquellas parcelas de la realidad, a las cuales parecía que las religiones no tendrían acceso (Berger, 1999). Otra carencia de dichos estudios es la señalada por Aranguren, de que su afán por atender la relación entre gestión de la ortodoxia y descalificación vía la herejía (Bourdieu, 1971) pierden de vista la tendencia a la heterodoxia, que opera en los umbrales de la Iglesia, pues se refiere a aquellos creyentes que optan por creer de manera diferente a los dogmas de su religión, pero no se salen de esa religión (Aranguren, 1994, p. 33). Esta situación, se ve cada día más dinamizada por los "buscadores espirituales" que, sin abandonar las grandes instituciones de la religión, se sitúan en los intersticios entre el dogma y la exploración de nuevas vías de experimentación de lo sagrado transversal, es decir, la atraviesa y la conecta en espacios de intersección entre campos diversos el papel que históricamente ha jugado la religiosidad popular como práctica que se resiste al orden dogmático y sacerdotal, donde se viven permanentemente los procesos de redefinición y reinterpretación del sentido práctico de la religión.

No obstante, la teorías basadas en los procesos de individuación de las creencias, nos hacen perder de vista los procesos de autentificación de las creencias que se encuentran enmarcadas en y reconfigurando el campo religioso. Ya Talal Asad (1993) había cuestionado este tipo de concepciones con las siguientes interrogantes: ¿cómo se autoriza lo religioso? 
y ¿qué papel siguen teniendo las religiones históricas en la definición y autorización de lo que es y no es religioso? La desinstiucionalización de nueva cuenta nos remite a atender procesos de lucha por la autorización entre las tendencias institucionales y los procesos subjetivos de lo que debe ser reconocido como religioso, más que a tendencias unilaterales ¿Acaso esta emigración de lo sagrado se da de manera libre a "tabla rasa"? ¿Este fenómeno no producirá tensiones, conflictos y resistencias institucionales? Es necesario por ende situarnos en el análisis de la tensión entre estructuras cognitivas de la sociedad (imaginarios, representaciones, ideas y creencias) y las estructuras de poder propias de las instituciones y de los campos especializados, visibilizados por el modelo teórico de Bourdieu. De aquí que, como ya lo he planteado en otros artículos, sostenga que la mejor forma de describir el fenómeno del cambio religioso, considerando las nuevas formas que adopta lo religioso, y las estrategias que implementa para legitimarse en tradiciones de larga duración (Hervieu-Lèger, 1993). Esto sugiere que habrá que posicionarnos en el entrecruce entre lo tradicional y lo emergente, entre lo local y lo transnacional, ente lo social y lo individual; entre la sacralidad profana (Piette, 1993) y la profanación de la religiosidad tradicional (Poulat, 1994).

Sería un error fijar las miradas en el adentro o en el fuera de las instituciones y/o de las tradiciones porque se perdería de vista las continuidades históricas de las culturas y sus agentes. Tampoco podríamos atender los procesos de autorización en la tradición. Por ello la propuesta es atender los cambios en los procesos espacios umbral, donde ambas lógicas interactúan para renovar en la continuidad. Esto nos permitirá esquivar la tentación de ponderar la acción de la producción secular de la creencia sobre los efectos de "vacío" (Díaz Salazar, 1994) o "estallido institucional" (Hervieu-Lèger, 1993); así como las estrategias de conquista u adaptación de la religión sobre los territorios seculares valorados como tierra de misiones (Poulat, 1994). Y lograr una mirada trasversal del fenómeno religioso.

\section{La religiosidad popular: particularidad histórica de la religión en América Latina.}

La religiosidad popular en América Latina, nos dice Cristian Parker (1993), ha sido históricamente el fermento de la cultura en América. Aunque a veces es sinónimo del catolicismo popular, es una expresión sincrética del choque cultural entre el catolicismo, introducido por los conquistadores con las cosmologías nativas (indígenas) y posteriormente con las religiones de origen africano que llegaron con el esclavismo negro. Por ello un rasgo propio es que floreció con una modalidad sincrética, y por tanto opera como 
matriz de creencias diversas, como lo señala Pierre Sanchis, para el caso brasileño, es:

Una fe en forma de religión. Y es por eso que, cuando se implanta en un espacio dominado por anteriores instituciones religiosas, ella tiende a operar por medio de transmutaciones de lo que parece posible asimilar y resemantizar en su propia síntesis. Su autoconcepción como una 'totalidad', 'la católica', lo predispone a esa estrategia, pues ella tiene más vocación para fagocitar que para excluir (Sanchis, 2008, p. 82).

Quizá este rasgo ayude a entender que en la religiosidad popular es donde aun en la actualidad se genera la mixtura entre varios sistemas religiosos: las cosmovisiones indígenas familiarizadas con la magia, el curanderismo, el animismo y el "paganismo", el catolicismo articulador de la devoción a los santos y vírgenes, el milagro y el ritualismo, pero también la espiritualidad nueva era y la neo esoteria. Aunque esta dos, son también matrices de sentido que retoman retazos de tradiciones exotizadas (desde oriente hasta occidente, desde la Patagonia hasta el Tíbet) y que son un signo de la religiosidad propia de la era de la globalización cultural, pues tienden a universalizar las religiones históricas, con las tradiciones esotéricas, con los nativismos exóticos, y con creencias seudocientíficas, en una amalgama que genera una yuxtaposición de fragmentos amalgamados.

Aunque pudiera parecer que todo está cambiando, al mismo tiempo es notoria la persistencia de las tradiciones religiosas de larga duración y la creación de nuevos cultos que se traduce en apariciones, cultos, rituales y peregrinaciones tradicionales. Como habíamos mencionado al inicio, en el caso mexicano una característica de la riqueza cultural y de permanencia de la religiosidad ha sido su carácter sincrético entre culturas autóctonas y las europeas. Por ello tanto la oferta neo esotérica como la sensibilidad nueva era no solo transitan sino se entrelazan con la religiosidad popular, lo cual les confiere una característica de hibridismo posmoderno, que se genera sobre condiciones culturales de sincretismo profundo entre tradiciones de resistencia y modernidad. El catolicismo oficial intentó desvirtuar las prácticas religiosas de las sociedades indígenas, denominando los antiguos cultos como idolatría, reduciendo sus conocimientos a supersticiones y prácticas de hechicería (Parker, 1993). A pesar de ello la creatividad de los pueblos en la recreación y apropiación popular del catolicismo permitió una resistencia histórica a los embates colonialistas.

La religiosidad popular, entonces, debe ser analizada como eje de tensión de la inculturación, si se mantiene vigente es por el dinamismo permanente 
entre la asimilación y el rechazo a la modernidad, entre la resistencia cultural de las tradiciones y su respuesta, no solo adaptativa, sino también performativa a la modernización contemporánea. Hace algunos años Rostas y Droogers señalaron que en la religiosidad popular se negocian permanentemente los procesos de redefinición y reinterpretación del sentido práctico de la religión; se confrontan las relaciones de dominación y resistencia, tanto entre la iglesia oficial y los creyentes, como entre las relaciones de clase:

Los usuarios de religiones (populares) están poco preocupados por el origen de sus creencias y prácticas y sí en cambio, por la eficacia de su versión de la religión. Ellos se apropian de símbolos y los aplican o los reinterpretan en situaciones particulares con el fin de ayudarse a sí mismos (a resolver sus situaciones financieras o a curarse da alguna enfermedad). Los usuarios de la religión popular no tienen escrúpulos acerca de mezclar e incorporar elementos a fin de satisfacer sus necesidades, independientemente de que ellas sean espirituales o materiales (Rostas; Droogers, 1995, p. 87).

Consideramos que en los rituales de religiosidad popular (aceptados, tolerados o rechazados por la institución católica) se construye el sentido colectivo de las nuevas formas religiosas, así como el espacio de referencia en donde se anclan a una autoridad legitimadora de una tradición que brinda un principio de identificación social y la posibilidad de incorporación a una comunidad creyente.

\section{Aportes desde el trabajo de campo para sortear las limitaciones teóricas: la religiosidad popular como "entre-medio"}

En este apartado buscaré enumerar algunos aspectos que nos ayudan a salir de de las dos paradojas conceptuales previamente descritas: la de una concepción sustantivisada de la religión que se ciñe a únicamente atender las prácticas institucionalizadas; y la vaguedad y nebulosidad impresa en las concepciones sobre las "nuevas formas de la religiosidad contemporáneas", que considero fueron un buen punto de partida para registrar lo religioso fuera de los templos, sin embargo goza de mucha imprecisión.

\section{Más que ser una espiritualidad paralela, es transversal a la institución}

Distintas encuestas sobre la correspondencia entre membrecía, creencias, valores y prácticas religiosas aplicadas en diferentes ciudades de América Latina (Parker, en Santiago de Chile; Fortuny, 1999 y De la Torre y Gutiérrez 
Zúñiga en Guadlajara/México, Malimacci en Buenos Aires/Argentina) constatan el desplazamiento de la institucionalización hacia la subjetivación de lo religioso. En la actualidad aunque el catolicismo continúa siendo mayoritario, estamos experimentando el paso a sociedades más diversas en cuanto a las opciones religiosas. Además de que cada vez hay más libertad para optar por mantenerse en la tradición católica o cambiar de religión, o decidir no tener religión alguna, los contenidos de las creencias se ven distanciados de los dogmas del cristianismo. Los imaginarios en la reencarnación, en pensar en la vida después de la muerte como unidad con el cosmos, o imaginar a Dios como fuerza vital al margen de la santísima trinidad, son ejemplos de la pérdida de autoridad de las iglesias, de sus figuras jerárquicas, y de símbolos de autoridad. Esta pérdida de dirección se recrudece aún más en la valoración ética de lo bueno y lo malo, del pecado y la virtud, en donde la postura eclesial frente a los temas relacionados con la sexualidad y la familia pierden plausibilidad entre los católicos. También en dichas encuestas se muestra que los creyentes combinan múltiples rituales, participando en los tradicionales católicos, pero no por ello dejando de experimentar en prácticas esotéricas, mágicas, o de espiritualidad nueva era. Asimismo, al menos en el caso mexicano, las creencias "precristianas" y prehispánicas perviven entretejidas con la religiosidad popular y son reactualizadas con atributos neoesotéricos y bajo reinterpretaciones de la nueva era para sanar el cuerpo y el espíritu (por ejemplo, las limpias, el curanderismo, el espiritismo, el chamanismo, la magia y la yerbería). Estos componentes de la religiosidad popular católica, en conjunto, son parte del patrimonio de las tradiciones y la cultura popular, y como tales, se implementan constantemente como puentes cognitivos para incorporar novedosos imaginarios y para domesticar las ansiedades y necesidades producidas por la globalización y el neoliberalismo. ${ }^{1}$

Por otro lado, hemos también descubierto (tanto a través de las encuestas como de las crónicas etnográficas y de las entrevistas) que en el presente aumenta una preferencia por la experimentación mística y por armar espiritualidades a la carta, que la mayoría de las veces son, como lo definió

El trabajo sobre el patrimonio cultural inmaterial de México, recién publicado por Lourdes Arizpe, constata estas transformaciones. En el capítulo dedicado a los usos y significados de la práctica del temascal en Amalcingo, se describe y analiza la manera en que las nuevas producciones religiosas, reconocidas de orientación nueva era, están contribuyendo a transformar los significados, los usos y los usuarios en la "revitalización" del baño del temascal, una de las prácticas de herencia mesoamericana, que hoy además de ser consideraras como patrimonio cultural, están siendo "reactualizadas" por agentes urbanos. A la vez documenta que dicho ritual, antiguamente practicada por los nativos, ya no es atractivo para ellos (Arizpe, 2009, p. 210-211). 
Cristián Parker, “catolicismos a mi manera". Ello caracteriza al buscador espiritual, al practicante de una religiosidad nómada, que emprende una búsqueda de lo religioso más allá de las iglesias.

\section{No son tan individuales: generan nuevos espacios de socialización y nuevas maneras de estar juntos}

Tanto a nivel de las creencias, como de las prácticas-- la producción, distribución y usos de los imaginarios religiosos están generando vías para emancipar y practicar la religiosidad al margen de los dogmas, las ortodoxas, las gestiones sacerdotales y las reglas propias de las iglesias. Dicha modalidad, conocida como desinstitucionalización, no sólo tiene repercusiones en las maneras de armar las creencias (en menús personales y a la carta) sino que también repercute en las nuevas formas de practicar y de generar rituales religiosos, los cuales son cada vez más heterodoxos y se ajustan a las nuevas necesidades de los creyentes, sea en los espacios tradicionales (como son los santuarios católicos ampliamente practicados por ser ejes de sociabilidad comunitaria o los centros de peregrinación por atraer amplias masas y generar sentidos de identidad regional) pero también en la actualidad, en busqueda de nuevas respuestas a los problemas de incertidumbre, se están creando nuevos santuarios, más efimeros y cercanos a la vida cotidiana y presentes en los "no lugares" (como son los altares en torno a santos seculares, las apariciones de la virgen de Guadalupe en los espacios de tráfico), o creando nuevos territorios consagrados para ritualizar las creencias mágico-esotérica, como pueden ser los rituales "neo paganos" de carga de energía los días de equinoccio y solsticio.

\section{¿Es tan nuevo lo nuevo?}

Francoise Champion (1995) definió la espiritualidad emergente bajo la metáfora de "nebulosa neo esotérica", a la cual describía como fragmentada, invisible y sin fronteras, si bien su aporte fue un punto de arranque que nos permitió constatar que había una nueva producción de creencias religiosas que se estaban reconfigurando al margen de las instituciones, de manera desinstitucionalizada y cada vez más subjetivada. No obstante, actualmente demanda nuevos abordajes conceptuales y metodológicos que lo convierta el fenómeno religioso en prácticas visibles, reancladas y socializadas. Para sortear este problema, la apuesta es atender las nuevas formas de la religiosidad moderna, no como producciones antagónicas o paralelas de lo tradicional y de la modernidad, sino como procesos transversales a la tradición, a la religión, a la memoria, etcétera. 
En el contexto actual, la revalorización de los conocimientos esotéricos antiguos y su vinculación con el mercado globalizado, ponderan estas prácticas como parte de una "nebulosa neo esotérica", que transite, busca, encuentra y toma prestado retazos de tradiciones que parecían olvidadas o relegadas a ámbitos marginales de la vida social, para proyectarlas como parte de una sabiduría cósmica y vanguardista. Sin embargo, un punto importante a destacar desde Latinoamerica es que así como el new age constituye una matriz a partir de la cual se resignifican y se transforman los sentidos de las prácticas populares; también la religiosidad popular opera como narrativa que reinscribe y traduce los símbolos y prácticas new age a su propia gramática de sentido.

Por su parte, no podemos privilegiar lo nuevo, como frecuentemente hacen los sociólogos europeos fascinados por descubrir las novedosas formas que toma la religiosidad, sin atender dos aspectos: la necesidad de lo nuevo de anclarse y legitimarse en los linajes creyentes de larga duración y la manera en que lo nuevo influye de manera decisiva en el resurgimiento (sea vía rescate o invención de las tradiciones) de lo antiguo. Por ejemplo, esto se hace evidente en la emergencia de movimientos neoindios, conformados por agentes urbanos cosmopolitas que se presentan como indios sin sufrir las condiciones marginales en que viven los indígenas (Gallinier; Molinié, 2006), inspirados en el movimiento New Age han contribuido al rescate y la reinvención de tradiciones de origen local que parecían amenazadas de extinción. Hoy algunas prácticas de hechicería, yerbería, chamanismo, danzas indígenas, cosmovisiones nativas, y ritualidades étnicas han sido incorporadas y resemantizadas como escuelas iniciáticas de un movimiento de alcances planetarios (De la Peña, 2002; De la Torre, 2008; y González Torres, 2006). Estas nuevas búsquedas de religiosidad mística son protagonizadas por agentes urbanos con mentalidad cosmopolita que recorren las tradiciones más apartadas de la occidentalización modernizante y van configurando sus propios menús creyentes, a la vez que contribuyen, como si fueran abejorros, a polinizar de significados y usos new age a las tradiciones en sus contextos locales (De la Torre, 2011).

En estas manifestaciones resaltan dos rasgos de la religiosidad contemporánea. El primero es que lo nuevo y lo tradicional se fusionan: se reinventan tradiciones, así como muchos de los nuevos relatos religiosos buscan legitimarse extendiendo una linaje imaginario con las tradiciones (Hervieu-Lèger, 1993). El segundo es que las distancias culturales se ponen en contacto, creando nuevos bricolajes con retazos de culturas y religiones antes lejanas y ausentes en los contextos locales, pero que gracias a los medios de comunicación se vuelven accesibles a todo el mundo. 


\section{¿Son tan invisibles y sin fronteras las nuevas formas de la religiosidad?}

Otra limitación encontrada en las teorías que aluden a la nebulosa esotérica, es que al definirla como algo invisible, fluido, sin fronteras, donde aparentemente todo se sintetiza con todo; se pierde de vista las diferencias en los procesos de apropiación de sentido, que no son unilaterales (desde lo global hacia lo local) sino que también operan en sentido contrario (en el de lo local hacia lo transnacional). De hecho un mismo símbolo o ritual, puede cambiar de sentido practicado si se inscribe en diferentes estanterías: por ejemplo la danza, practicada por un mismo grupo, puede estar inscrita en un acto devocional católica, y se vivida como ofrenda votiva a la virgen, mientras que si se expone en Expo Yoga se oferta como una práctica de "meditación en movimiento" o de "yoga en movimiento" equiparándola con las técnicas new age de conocimiento personal; por su parte si se práctica en una celebración de equinoccio en un santuario neopagano (como son los centros arqueológicos) se le da un sentido de rescate de las raíces de la mexicanidad (Gutiérrez, 2008).

\section{Lo individual no quita la alteridad cultural}

Por otro lado, asumir que los menús individualizados de creencias, se resuelven con una suerte de metáfora del bricolaje, que genera una síntesis amorfa; desdibuja las recomposiciones semióticas que no solo generan identificaciones, sino también alteridades al interior de esta suerte de vago eclecticismo. Por ejemplo, en el trabajo de campo, al realizar entrevistas con distintos sujetos que tienen amplias trayectorias de buscadores espirituales, podemos apreciar diferencias en la identificación y en el armado narrativo de sus propios menús creyentes. Por ejemplo, Jobita, una mujer de origen popular, que asistió al instituto kundalini para capacitarse en magia blanca, incorporó los nuevos saberes esotéricos para reencontrarse con su historia de un catolicismo popular mágico, practicado por su padre, que ella denuncia se perdió con el catolicismo contemporáneo. Para ella lo nuevo está en los significantes, más no en los contenidos. Las nuevas experiencias, símbolos y técnicas de magia blanca las traduce desde su propia matriz de sentido del catolicismo sincrético: por ejemplo las vibras y energías son equiparadas con los espíritus que se manifestaban en formas del catrín (el demonio representado bajo la forma del caballero elegante vestido de negro), el culto al Ángel de la guardia con los ángeles guardianes, el Karma con la idea providencialista del destino, el incienso con la función simbólica del agua bendita. 
De manera contrastante, tenemos el caso de la líder del un movimiento new age llamado misioneros azules, que reinterpretan las imágenes y rituales católicos desde una matriz con significados nueva era: visualización, concepción kundalini del cuerpo y técnicas de yoga, armonía planetaria, transformación de la conciencia). Actualmente ella difunde dirige el grupo Misioneros azueles cuya actividad principal es realizar meditaciones y clases de metafísica guiadas, con la siguiente meta, netamente nueva era: "hay que lograr la unidad del planeta. Sin distinción de religiones ni de razas, todas las creencias nos llevan a la existencia del mismo Dios. Hay que equilibrar las energías de este planeta para lograr la armonía, para elevarnos de nivel”. Tanto en sus talleres como en su programa de radio los conceptos new age están presentes en los significantes de la devoción católica tradicionales: la Virgen, los santos, las ángeles de la guardia, Cristo, o Dios padre, todos son guías espirituales. Para ella, los guías se pueden presentar bajo diversas formas y diversas personalidades, pero "todo es lo mismo" (De la Torre, 2011).

\section{Están mediadas por las industrias culturales}

A pesar de ser un fenómeno cada vez más distante de la institución y cada vez más subjetivado, habrá que recalcar que éste no es un fenómeno individual. Está mediado por distintas fuentes de construcción de sentido social, incluso algunos de alcance nacional y/o global. Como son la mercantilización de las creencias, ceremonias, tradiciones, saberes y símbolos provenientes de las religiones. Esta mercantilización se hace presente en la explotación turística de las espiritualidades nativas, en la difusión milagrosa de santos y vírgenes producidas a escala masiva en China, en la integración de retazos de tradiciones en las estanterías exotéricas (ferias y expo esotéricas), y en la incorporación publicitaria de los valores new age para la venta de productos que ofrecen una forma de consumo alternativo. Está gramática de la seducción alienta una religiosidad de consumo abierta a la libre elección y a la personalización de los menús creyentes.

Si bien no podemos hablar de una religiosidad de supermercado, sí es un hecho que aún las devociones más tradicionales están mediadas por la mercantilización y el consumo intensivo de símbolos, mensajes, talleres terapéuticos. El consumo pone en marcha los itinerarios de los buscadores espirituales, que como lo demuestra Magnani, que recorren circuitos donde se ofertan distintos elementos que son retomados para conformar su propio menú de creencias y experiencias religiosas (Magnani, 1999). Su difusión global transterritorializa y globaliza algunos componentes de las religiones generando bricolajes y contenido híbridos entre las religiones de oriente y de 
occidente; entre la magia y el catolicismo, entre lo indio y la nueva era. La religiosidad del consumo está también intensamente mediada por los mensajes mediáticos, la literatura de auto ayuda (Semán, 2005), la ciencia, ficción y la literatura (De la Torre, 2008), las fórmulas milagrosas de mercancías y literatura esotérica que operan como talismanes mágicos (De la Torre y Mora, 2002), y la industria de la música (el caso más estudiado es el de la relación entre pentecostalismo y música) y los teleevangelistas (un caso paradójico en América latina es la denominación brasileña Iglesia Universal del Reino de Dios, estudiada por Mariano, 2003).

\section{No solo son eclécticas sino que reinventan la tradición étnica}

Los contenidos neo tradicionales de las religiosidades populares no sólo son sincréticos, sino cada vez más eclécticos: combinan elementos de la devoción católica, fusionados con los saberes y creencias residuales de los rituales indígenas y las creencias mágicas, los cultos afroamericanos y los cultos paganos a la naturaleza y la energía. Pero además recientemente incorpora y es resemantizada por nuevas narrativas difundidas ampliamente por la sensibilidad nueva era y por el sentido mágico de la neoesoteria. Retoma los elementos de alteridad de la cultura occidental: las prácticas orientales, las prácticas nativas precristianas, y los ritos paganos que se vuelcan a la consagración de la naturaleza. Recupera antiguas tradiciones indígena y/o africanas, que están siendo revitalizadas, reinventadas y a la vez reesencializadas por narrativas literarias (como es el caso del movimiento de la neomexicanidad inspirado en la novela de Regina, o la inspiración de chamanes urbanos en la búsqueda de las enseñanzas de Don Juan) e incluso literatura de ciencia ficción (por ejemplo los comulgantes con las creencias de los iluminatis, los secretos de los templarios o los hijos de la matrix). Las clases populares prefieren recorrer el mercado de ofertas mágicas y neo esotéricas para resolver problemas cotidianos (principalmente: salud, dinero y amor); por su parte las clases medias urbanas optan por la búsqueda interior que va desde la yoga, la meditación kundalini hasta las experiencias con yajé, peyote, hongos alucinógenos. Además establecen contactos con indios que son considerados maestros o guardianes de las culturas autóctonas, pues consideran que sus ritualidades son caminos para armonizar con la naturaleza (la madre tierra o pachamama), y para reactivar las energías cósmicas (De la Torre, 2006).

\section{Reflexiones finales}

En América Latina, la religiosidad contemporánea, a diferencia de la propuesta de Champion y Hervieu-Lèger, no se encuentra diseminada 
y fragmentada en percepciones individualizadas, sino más bien está constantemente generando anclajes en las prácticas más tradicionales, incluso en aquellas que, como ya señalamos, son consideradas como más ancestrales, más populares, más nacionales, o más naturales.

Es por ello, que es sumamente complicado sostener la distinción clara entre las dinámicas propias de las nuevas formas contemporáneas de la religiosidad y las dinámicas de los usos populares de lo religioso y de su también incesante capacidad sincrética. Ante esto surgen las siguientes preguntas: ¿Cómo precisar el cambio religioso sin tener claro el antes y el después? ¿Lo que hoy en día se aprecia como impacto de la secularización podría ser una derivación de procesos de larga duración, como por ejemplo la religiosidad popular? ¿Son nuevas o son antiguas? Dar respuestas encuentra dificultades, debido a que las manifestaciones se yuxtaponen constantemente lo novedoso con lo tradicional. Por ejemplo, muchas nuevas formas de lo religioso se basan en el rescate de ritualidades prehispánicas (danzas concheras y aztecas, temaxcales, danza del sol) o preincas, o en la búsqueda y esencialización de rituales nativistas (ritual del peyote, religión del Santo Daime, toma ritual del yajé). En estas prácticas, el rescate de lo autóctono, se realiza a partir de una invención de los cultos ancestrales. Ficcionalización y rescate de formas puras van de la mano, y, aunque suene paradójico, la interacción entre ambos permite la continuidad de las raíces, a la vez que genera que lo nuevo, de recién aparición, se legitime en tradiciones de larga duración, y que construya linajes de continuidad con tradiciones de creencias antiguas (De la Torre, 2011).

Mi propuesta entonces es estudiar el reacomodo constante, de ida y vuelta entre lo nuevo y lo tradicional, saliendo de las instituciones, pero mirando hacia su recomposición, dando seguimiento a las movilidades, pero sin perder de vista los enraizamientos en la tradición. Por ello, sostengo que el lugar estratégico para lograr esta mirada sea atendiendo los escenarios donde se práctica la religiosidad popular. Ésta, como lo sugiere Bahbha, representa un entre-medio (in-between $)^{2}$ la institución y las prácticas culturales, lo ancestral y lo nuevo, lo hibrido y las reinvenciones esencializadoras, lo local y lo global, entre lo individual y lo social, la movilidad y la permanencia. Es un espacio umbral de negociación constante donde se tradicionaliza lo emergente, y se construye la vigencia de lo antiguo, donde lo global se enraíza, y las raíces étnicas y nativistas se transnacionalizan. No sólo representa un residuo del pasado, sino el dinamismo constante, en que se redefine lo nuevo y lo tradicional, dotando

2 Espacio de representación que amenaza la división binaria con su diferencia" (Bahbha, 2010, p. 395). 
de continuidad y anclaje territorial a las nuevas situaciones, prácticas y formas culturales que provienen de lugares inaccesibles en el tiempo y el espacio convencional y próximo (De la Torre, 2001, p. 205).

\section{Referencias}

ARANGUREN, José Luis. La religión hoy. In: DÍAZ SALAZAR, R.; GINER. S.; VELASCO, F. (eds.). Formas modernas de religión. Madrid: Alianza Universidad, 1994.

ARIZPE, Lourdes. El patrimonio cultural inmaterial de México. Ritos y festividades, Miguel Ángel Porrúa, Conaculta/Crim/Unam, 2009.

ASAD, Talal. Genealogies of Religion. Discipline and reasons of power in christianity and islam, Baltimore and London: The Johns Hopkins University Press, 1993.

BAHBHA, Homi K. DisemiNación. Tiempo, narrativa y los márgenes de la nación moderna. In: BAHBHA, K. (comp.). Nación y narración. Entre la ilusión de una identidad y las diferencias culturales. México: Siglo XXI editores, 2010. p. 385-424.

BARKER, Eileen. New religious movements: a practical Introduction. London: Her Majesty Stationary Office, 1992.

BERGER, Peter (ed.). The seculariztion of the morld. Resurgent religion and the work politics, Washington: Ethics and Public Policy Center, 1999.

BOURDIEU, Pierre. Genèse et structure du champ religieux. Revue française de Sociologie, Paris, v. XII, p. 295-334, 1971.

CHAMPION, Francoise. Persona religiosa fluctuante, eclecticismo y sincretismos. In: DELUMEAU, Jean (dir.). El hecho religioso. Enciclopedia de las grandes religiones. Madrid: Alianza Editorial, 1995. p. 705-737.

De la PEÑA, Francisco. Los hijos del Sexto Sol, México: INAH, 2002.

DE LA TORRE, Renée. El catolicismo: ¿un templo en el que habitan muchos dioses? In: FORTUNY, Patricia (coord.). Creyentes y creencias en Guadalajara. México: Ciesas/Conaculta/Inah, 1999. p. 133-163.

DE LA TORRE, Renée. Religiosidad popular. Anclajes locales de los imaginarios globales, Metapolítica, v. 5, p. 98-117, enero marzo 2001.

DE LA TORRE, Renée. Circuitos mass mediados de la oferta neo esotérica: el new age y la neo magia popular en Guadalajara. Revista Alteridades, UAM Iztapalapa, año 16, n. 32, p. 27-39, 2006.

DE LA TORRE, Renée. Tensiones entre el esencialismo azteca y el universalismo New Age a partir del estudio de las danzas "conchero-aztecas". Revista Trace, México: Cemca, n. 54, p. 61-76, Diciembre 2008.

DE LA TORRE, Renée. Les rendez-vous manqués de l'anthropologie et du chamanisme (Introducción del dossier Religions amérindiennes et New Age). Archives de Sciences Sociales des Religions, Paris: éditions de L'École des Hautes Études en Sciences Sociales, n. 153, 56 anné, p. 145-158, enero-marzo 2011. 
DE LA TORRE, Renée. Religiosidad nómadas. Creencias y prácticas heterodoxas en Guadalajara.México: Ciesas, 2012.

DE LA TORRE, Renée; MORA, José Manuel. Itinerarios creyentes del consumo neo esotérico, Revista Comunicación y Sociedad, DECS de la Universidad de Guadalajara, Guadalajara, n. 39, p. 113-144, enero-junio 2002.

DÍAZ SALAZAR, Rafael. La religión vacía. Un análisis de la transición religiosa en Occidente. In: DÍAZ SALAZAR, R.; GINER, S.; VELASCO, F. (eds.) Formas modernas de Religión. Madrid: Alianza Universidad, 1994. p. 71-116.

DAVIS, Grace. Croire sans appartenir: le cas britanique. In: DAVIS, Grace; HERVIEULÈGER, Danièle (eds.) Identités religieruses en Europe. Paris: La découverte, 1996, p. 175-194.

FORTUNY, Patricia (coord.). Creyentes y creencias en Guadalajara. México: Ciesas/ Conaculta/Inah, 1999.

GALLINIER, Jacques; MOLINIÉ, Antoinette. Les néo-indiens. Une religión du III ${ }^{\mathrm{e}}$ millénaire. Paris: Odil Jacob, 2006.

GONZÁLEZ TORRES, Yólotl. Danza tu palabra. La danza de los concheros. México: Conaculta/Inah/Plaza y Valdés, 2006.

GUTIÉRREZ ZÚÑIGA, Cristina. La danza neotradicional como oferta espiritual en la estantería exotérica new age. In: ARGYRIADIS, K.; DE LA TORRE, R.; GUTIÉRREZ ZÚÑIGA, C.; ROS, Aguilar A. Raices en movimiento. Prácticas tradicionales en contextos translocales. México: Ciesas/ElColJal/IRD7Cemca/Iteso, 2008.

HEELAS, Paul; WOODHEAD, Linda. The spiritual revolution. Why religion is giving way to spirituality. Blackwell: Oxford, 2005.

HERVIEU-LÈGER, Daniéle. La religion pour mémoire. Paris: les éditions du Cerf, 1993.

HERVIEU-LÈGER, Daniéle. El peregrino y el convertido. La religión en movimiento. México: ediciones del Helénico, 2004.

HERVIEU-LÈGER, Daniéle. Por una sociología de las nuevas formas de religiosidad: algunas cuestiones teóricas previas. In: GIMÉNEZ, Gilberto (comp.). Identidades religiosas y sociales en México. México: Ifal/Unam, 1996. p. 23-46.

HERVIEU-LÈGER, Danièle; CHAMPION, Françoise (eds.). De l'emotion en religion. Renouveau et traditions. Paris: Centurion, 1990.

MALLIMACI, Fortunato. A situação religiosa na argentina urbana do fim do milênio. In: ORO, Ari Pedro; STEIL, Carlos Alberto Steil (Orgs.). Globalização e religião. Petrópolis: Editora Vozes, 1999.

MAGNANI, José Guilherme. O circuito neo-esotérico na cidade de São Paulo. In: CAROZZI, Maria Julia (ed.). A Nova Era no Mercosur. Petrópolis: Vozes, 1999. p. 27-46.

MARIANO, Ricardo. Brésil. In: CORTÉN, André; DONZON, Jean Pierre; ORO, Ari Pedro (comps.). Les nouveaux conquérants de la foi. Paris: Karthala, 2003. p. $45-57$. 
MARDONES, José María. Religión y mercado en el contexto de transformación de la religión. Desacatos, Revista de Antropología social, Mercado y religión contemporánea, México-Ciesas, n. 18, p. 103-110, mayo-ago. 2005.

PARKER, Cristián. Otra lógica en América Latina. Religión popular y modernización capitalista. Santiago de Chile: Fondo de Cultura Económica, 1993.

PARKER, Cristián. Las nuevas formas de la religión en la sociedad globalizada: un desafío a la interpretación sociológica. Ponencia presentada en la 26th Conference of the International Society for the Sociology of Religion, Ixtapán de la Sal, México, 2001.

PIETTE, Albert. Implication paradoxale. Mode mineur et religiosités séculières. Archives de Sciences Sociales des Religions, año 38, p. 63-78, enero-marzo 1993.

POULAT, Emile. L'ere postchretienne. Paris: Flammarion, 1994.

PRATT, Mary Louise. Modernidades, otredades, entre-lugares. Desacatos, Revista de Antropología Social. Modernidad y ciudadanía a fin de siglo. México: Ciesas, n. 3, p. 21-38, 2000.

PRATT, Mary Louise. Por qué la Virgen fue a los Ángeles. Reflexiones sobre la movilidad y la globalidad. A Contra corriente, Revista de Historia Social y Literatura de América Latina, v. 3, n. 2, p. 1-3, 2006. Consultada en: <http://www.ncsu.edu/ project/acontracorriente/winter_06/Pratt.pdf>.

ROSTAS, Susanna; DROOGERS, André. El uso popular de la religión popular en América Latina: una introducción. Revista Alteridades, México: UAM-Iztapalapa, v. 5, n. 9, p. 81-91, 1995.

SANCHIS, Pierre. Cultura brasileira e religião... passado e atualidade... Cuadernos Ceru, Rio de Janeiro, série 2, v. 19, p. 71-92, 2008.

SEMÁN, Pablo. ¡Por qué no? El matrimonio entre espiritualidad y confort. Del mundo evangélico a los bestsellers. Desacatos, Revista de Antropología Social. Mercado y religión contemporánea, México: Ciesas, n. 18, p. 71-86, 2005. 